\title{
Bronchoalveolar Lavage Profiles in Uncontrolled Wheezy Children Compared by Asthma Predictive Index
}

\author{
Dima Ezmigna ${ }^{1}$, Mark Brown $^{2}$, Cori Daines $^{3}$, and Wayne Morgan ${ }^{4}$ \\ ${ }^{1}$ University of Florida \\ ${ }^{2}$ University of Colorado Denver School of Medicine \\ ${ }^{3}$ University of Arizona College of Medicine \\ ${ }^{4}$ The University of Arizona College of Medicine Tucson
}

April 16, 2021

\begin{abstract}
The Asthma Predictive Index (API) predicts later asthma in preschoolers with frequent wheeze. We hypothesized that airway cytology differs between API positive(+ve)/negative(-ve) children with uncontrolled/recurrent wheezing with dominance of eosinophils in API (+ve) and neutrophils in API (-ve) groups respectively. Objective: To compare bronchoalveolar lavage (BAL) cell profiles in API (+ve)/(-ve) children with recurrent wheezing unresponsive to inhaled corticosteroids (ICS). Design: A retrospective analysis of BAL in 43 children, 3-36 months (median: 14 months) receiving ICS (31 API + ve ; 12 API ve). BAL cell differential counts, bacterial/viral cultures, and lipid-laden macrophage percentages (LLM) were analyzed. Cell counts presented as median (range). Results: Neutrophil percentages were increased in both groups [API -ve 16\% (1-76\%); API +ve $42 \%$ (1-95\%); $\mathrm{P}=\mathrm{NS}$ ]. Cell percentages were similar for lymphocytes [API-ve 12\% (1-30\%); API +ve 7\% (1-37\%)], and macrophages [API -ve $67.5 \%$ (12-97\%); API + ve $41 \%(2-94 \%)$ ]. Eosinophil percentages were low in both groups [API -ve $1 \%$ $(1-2 \%)$; API + ve $1 \%(1-11 \%)]$. Bacterial cultures were positive in $16(80 \%)$ API +ve and $4(33 \%)$ API -ve patients $(\mathrm{P}=0.10)$. Conclusion: Cell profiles do not differ between API groups in children [?]36 months with recurrent wheezing unresponsive to ICS. Positive correlation between neutrophil percentages and positive bacterial cultures was seen independent of API. Persistent bacterial bronchitis likely plays an important role in the persistence of symptoms unresponsive to inhaled corticosteroid therapy regardless of API status with a trend to more positive cultures in API positive children.
\end{abstract}

\section{Bronchoalveolar Lavage Profiles in Uncontrolled Wheezy Children Compared by Asthma Pre- dictive Index}

Dima Ezmigna MBBS ${ }^{1}$, Mark Brown $\mathrm{MD}^{2}$, Cori Daines $\mathrm{MD}^{3}$, Wayne Morgan $\mathrm{MD}^{3}$

1. Department of Pediatrics, University of Florida, Gainesville

2. Department of Pediatrics, Children's Hospital Colorado, Aurora

3. Department of Pediatrics, The University of Arizona, Tucson

Correspondence:

Dima Ezminga, MBBS

1600 SW Archer Road

Gainesville, FL, 32606

$352-273-8381$

Fax: 352-294-8098 
dezmigna@ufl.edu

Key words: Wheezing, Asthma, Bronchoalveolar Lavage, Protracted bacterial Bronchitis

Running head: Bronchoalveolar Lavage Compared by Asthma Predictive Index

Abstract:

The Asthma Predictive Index (API) predicts later asthma in preschoolers with frequent wheeze. We hypothesized that airway cytology differs between API positive(+ve)/negative(-ve) children with uncontrolled/recurrent wheezing with dominance of eosinophils in API (+ve) and neutrophils in API (-ve) groups respectively. Objective: To compare bronchoalveolar lavage (BAL) cell profiles in API (+ve)/(-ve) children with recurrent wheezing unresponsive to inhaled corticosteroids (ICS). Design: A retrospective analysis of BAL in 43 children, 3-36 months (median: 14 months) receiving ICS (31 API +ve ; 12 API -ve). BAL cell differential counts, bacterial/viral cultures, and lipid-laden macrophage percentages (LLM) were analyzed. Cell counts presented as median (range). Results: Neutrophil percentages were increased in both groups [API -ve 16\% (1-76\%); API +ve 42\% (1-95\%); P=NS]. Cell percentages were similar for lymphocytes [API-ve $12 \%(1-30 \%)$; API + ve 7\% (1-37\%)], and macrophages [API -ve 67.5\% (12-97\%); API +ve $41 \%(2-94 \%)$ ]. Eosinophil percentages were low in both groups [API -ve $1 \%(1-2 \%)$; API +ve 1\% (1-11\%)]. Bacterial cultures were positive in $16(80 \%)$ API +ve and $4(33 \%)$ API -ve patients $(\mathrm{P}=0.10)$. Conclusion: Cell profiles do not differ between API groups in children [?]36 months with recurrent wheezing unresponsive to ICS. Positive correlation between neutrophil percentages and positive bacterial cultures was seen independent of API. Persistent bacterial bronchitis likely plays an important role in the persistence of symptoms unresponsive to inhaled corticosteroid therapy regardless of API status with a trend to more positive cultures in API positive children.

\section{Introduction:}

Asthma continues to be a leading chronic childhood illness in the US. The prevalence among children less than 18 years of age remains at $7.5 \%^{1}$. Approximately $30 \%$ of wheezy infants and toddlers continue to wheeze at the age of $\operatorname{six}^{2}$. Wheezing in young children includes a heterogeneous group of patients, and whether an infant or a young child is expected to develop asthma remains a challenging clinical question.

In an effort to understand the natural history of asthma, several epidemiological studies have developed different classifications of wheezing phenotypes ${ }^{3,4,5}$. Using data from the Tucson Children's Respiratory Study ${ }^{3}$, the Asthma Predictive Index ${ }^{6,7}$ (API) was developed in 2000 to predict the future development of asthma in young preschool children with frequent wheeze. Since then, the API has been well validated and internationally supported in clinical practice as well as in pediatric asthma research ${ }^{8,9}$. Few studies, however, have been carried out looking at airway inflammation in early childhood, to elucidate the underlying pathophysiology and correlate those findings with what is known about wheezing phenotypes and outcomes ${ }^{10-14}$.

Based on the current knowledge of the role of airway inflammation in wheezing, anti-inflammatory therapy, specifically inhaled corticosteroids (ICS), remain the first line therapy for persistent asthma in all age groups, including preschool children. ICS are recommended by the National Asthma Education and Prevention Program (NAEPP) ${ }^{15}$ for daily use in children at high risk for asthma (positive API), and by the Global Initiative of Asthma (GINA) guidelines in its most updated document for all preschool children with recurrent wheezing ${ }^{16}$. ICS have proven efficacy in controlling inflammation, reducing asthma symptoms and reducing the frequency of exacerbations in this age group. However, they do not modify the long term outcome ${ }^{17}$. In the case of persistence of symptoms while receiving ICS, a thorough workup is strongly recommended to exclude other causes of wheezing ${ }^{18}$. This includes flexible bronchoscopy to examine airway anatomy and dynamics and obtain a bronchoalveolar lavage (BAL) for cytology and culture. Utilizing BAL cytology is one of the methodologies that has contributed to understanding the underlying inflammatory processes responsible for asthma and perhaps the structural remodeling that is sometimes seen. In recent years, the role of protracted bacterial bronchitis (PBB) and airway infection in recurrent wheeze has become clearer 
19-21. PBB is recently recognized by the European Respiratory Society as one of the most common causes of chronic wet cough in children with or without wheezing in the absence of other underlying causes. It is often misdiagnosed as or found to exacerbate existing asthma leading to increased usage of ICS. It usually responds to treatment with antibiotics of 2-4 weeks duration ${ }^{21}$.

We undertook this retrospective analysis to clarify the underlying causes of recurrent wheeze in infants and pre-school aged children unresponsive to low to moderate dose ICS treatment and to determine whether the two API (positive and negative) groups differed in their BAL inflammatory profiles. We specifically wished to ascertain whether the risk of PBB differed between these two groups. We hypothesized that eosinophilic inflammation would predominate in the airways of children with positive API compared to neutrophilic inflammation for children with negative API.

\section{Method:}

We conducted a retrospective review of the medical records and bronchoalveolar lavage cell profiles of all children 3-36 months of age who underwent flexible bronchoscopy and BAL analysis for uncontrolled recurrent wheezing, between September 2009 and August 2011.

Patients' records were selected from among those being seen in the University of Arizona Pediatric Pulmonology outpatient clinics, with persistent wheezing on ICS, and who were scheduled for diagnostic bronchoscopy and BAL examination as part of the clinical workup for the persistence of symptoms. The decision to perform a diagnostic bronchoscopy was made by a pediatric pulmonologist based on clinical grounds after detailed assessment of symptoms, self-reported adherence to therapy, dosage of ICS and assurance of adequate technique of inhaled medication administration. Sweat chloride determination was normal for patients who were tested. Uncontrolled wheezing was defined by the persistence of symptoms despite treatment with low to moderate doses of ICS (doses as defined by GINA guidelines: fluticasone propionate 44mcg 2 puffs bid or $110 \mathrm{mcg} 2$ puffs bid or budesonide nebs $0.25 \mathrm{mg}$ bid or $0.50 \mathrm{mg}$ bid) for at least 4 weeks, and the need to use short acting bronchodilator therapy more than two days per week. Patients with comorbidities were excluded, including those with a history of congenital airway anomaly, known immunodeficiency, congenital heart disease, chronic lung disease of prematurity or prematurity with prolonged endotracheal intubation, and neurological and chromosomal abnormalities. None of the patients were symptomatic at the time of bronchoscopy or had received antibiotics in the 4 weeks preceding the procedure. The modified asthma predictive index ${ }^{8}$ was used to classify patients into API positive (+ve) and negative (-ve) groups by retrospective chart review. BAL differential cell counts, bacterial cultures, viral cultures, and proportion of lipid laden macrophages (LLM) were analyzed. A positive bacterial culture indicating infection was defined by the presence of [?]10 ${ }^{4}$ colony forming units (CFU) per $\mathrm{ml}$ of a single organism. Elevated LLM proportion was defined as [?] 20\%. (A proportion of $20 \%$ in our lab correlates with LLM index between 80-100). No control group of healthy infants was available for this retrospective analysis. Therefore, our findings were compared to normal values published in the pediatric pulmonary literature ${ }^{22}$. We defined normal cell count percentages as follows: neutrophils $<10 \%$, lymphocytes $<8 \%$, macrophages $80-90 \%$ and eosinophils $<2 \%^{22}$.

\section{Statistical analysis:}

We used non-parametric statistics due to the non-normal distribution of BAL cytology results. Two sample Wilcoxon- rank sum (Mann-Whitney) test was used to study statistical significance comparing groups. For correlation, Spearman's rank test was used for non-parametric correlation and Chi-square for 2 categorical variables. A p-value $<0.05$ was considered significant. Cell counts are presented as median percent and range. Analyses were conducted with STATA 9 (StataCorp-Texas,USA ).

\section{Flexible bronchoscopy and BAL:}

Informed consent for the procedure was obtained from parents/guardians of patients before each bronchoscopy, which were all clinically indicated as part of the patients' evaluations for persistent wheezing. The bronchoscopies were done under inhalational anesthesia. The BAL was obtained from the right middle lobe unless otherwise prompted by more inflammation in other anatomical locations. We used a maximum 
of three aliquots of $10 \mathrm{ml}$ each. The three aliquots were pooled and sent as one sample for analysis and culture (bacterial, viral). The $2.8 \mathrm{~mm}$ (Olympus XP 160) pediatric flexible fiberoptic bronchoscope was used in all procedures. The scope was introduced through a laryngeal airway to reduce contamination of the bronchoscope with naso-oropharyngeal flora.

\section{Ethical Considerations:}

This retrospective chart review was approved by the University of Arizona Institutional Review Board (IRB) and waiver of consent was obtained.

Results:

Records from a total of 43 children [?] 36 months old [median 14 months (range 3-36 months)] on ICS therapy were included in the analysis. The majority of patients were API positive. (Table 1). Median BAL eosinophil percentages were low in both API -ve and API + ve groups and were comparable to expected normal values from the literature ${ }^{17}$ with a median (range)of $1 \%(1-2 \%)$ in API -ve and $1 \%$ (1-11\%) in API + ve patients (Figure 1-a). Only 3 patients with +ve API had eosinophils [?] 2\%. Increased neutrophil percentages compared to literature controls ${ }^{17}$ were present in both API groups with a median $16 \%$ neutrophils (1-76\%) in API -ve and $42 \%$ neutrophils $(1-95 \%)$ in API +ve patients; $(\mathrm{P}=0.09)$. (Figure 1-a). Cell percentages (median (range)) were similar for lymphocytes and macrophages between API groups with $12 \%$ lymphocytes (1-30\%) in API -ve and 7\% lymphocytes (1-37\%) in API +ve groups; $67.5 \%$ macrophages (12-97\%) in API -ve and $41 \%$ macrophages (2-94\%) in API + ve groups (Figure 1-a). No difference was found between any cell type percentage comparing API groups after exclusion of samples with positive BAL cultures (bacterial and viral) (Figure 1-b); however, neutrophil percentages remained higher than expected in both groups. Patients with positive cultures (bacterial or viral) had significantly higher neutrophil percentages compared to patients with negative cultures in both API groups in combined $(p=0.0001)$. (Figure 2, Table 2).

There was no significant difference in culture results (bacterial and viral) comparing API groups (Table 1). There was correlation between neutrophil percentages and positive bacterial $(\mathrm{R}=0.6, \mathrm{p}<0.001)$ and viral cultures $(\mathrm{R}=0.3, \mathrm{p}=0.01) .25 \%$ of total patients had mixed (bacterial and viral) cultures. $M$. catarrhalis was the most commonly isolated organism (8 patients), followed by Streptococcus pneumoniae (5 patients) and a significant growth of mixed organisms (5 patients). Two patients grew H. influenzae. Viruses isolated include Rhinovirus (3 patients) Coxackie/Echo virus (4 patients), Adenovirus (2 patients) and CMV (1 patient). Three patients had a mixed culture of CMV with another virus (Rhinovirus, Coxackie virus and Corona virus). One patient had a mixed culture of Adenovirus with Parainfluenza virus. Thirty three percent of all patients had LLM\% [?] $20 \%$ in their BAL; however, LLM\% did not differ by API, culture status, or cell percentages.

\section{Discussion:}

We compared BAL cytology in children [?] 36 months with recurrent wheezing whose symptoms were uncontrolled on ICS therapy. We characterized them by their Asthma Predictive Index status and evaluated BAL culture results. All of our patients were receiving the same dose range (low to moderate dose) of ICS independent of API status. We found no significant difference in any cell-type percentages between positive and negative API groups. Although neutrophilic inflammation was seen in both API groups, there was a trend for it to be higher in API + ve children (median of $42 \%$ vs $16 \%, \mathrm{p}=0.09$ ); however, this difference was not statistically significant probably due to the small sample size in this retrospective study.

In our analysis, evidence of infection was common. Almost $60 \%$ of children had positive bacterial cultures, Thus, a significant proportion of our patients had persistent bacterial bronchitis (PBB); i.e. the presence of a significant count of a bacterial pathogen along with elevated neutrophils, to explain their uncontrolled inflammation and persistence of respiratory symptoms despite ICS therapy. PBB has been proposed as an important cause of persistent wheezing in young children as well as potentially implicated in triggering acute wheezy episodes ${ }^{10}$. Bisgaard et $\mathrm{al}^{23}$ demonstrated that bacterial colonization in healthy neonates was associated with an increased risk of subsequent recurrent wheezing and asthma. We demonstrate similar 
findings and believe that bacterial infection of the lower respiratory tract can be responsible for persistent wheezing and unresponsiveness to conventional therapy, regardless of API status. Our findings suggest that the diagnosis of PBB should be addressed by obtaining BAL or sputum sample for culture or by empiric antibiotic treatment before proceeding to a higher dose ICS or adjunctive therapy, given good adherence to therapy and proper inhalation technique. The concomitant presence of viruses in the infected BAL may suggest an initial viral infection with abnormal clearance of the respiratory secretions and subsequent infection by the most abundant respiratory bacterial pathogens, although Bisgaard et al ${ }^{10}$ showed $40 \%$ carriage rate of viruses in the respiratory tract of asymptomatic children. We found a strong correlation between positive viral and bacterial cultures in our analysis $(\mathrm{p}=0.02)$ in contrast to the findings by Bisgaard et $\mathrm{al}^{10}$.

To differentiate between colonization and infection, we have chosen a cut-off value for bacterial colony count of $[?] 10^{4} \mathrm{CFU} / \mathrm{ml}$ for each pathogen to define infection. To avoid contamination of BAL samples by nasopharyngeal species, we followed a strict technique of not using the suction channel before complete wedging in a sub-segmental airway. Furthermore, the examination of nasopharynx (as part of the patient's comprehensive airway evaluation) was performed after obtaining BAL samples. An interesting group of patients are those who had sterile cultures and normal BAL cytology $(\mathrm{n}=18,41 \%)$, and were uncontrolled on conventional asthma therapy, with no difference by API status. The etiology of their symptoms remains unclear.

Our results are similar to those of Krawiec et al ${ }^{11}$ with a generalized inflammatory response marked by elevation in total cell counts with no dominance of any cell type in a group of similar age in which they excluded positive bacterial cultures, and viral studies were not performed. However, not all patients had received ICS. In contrast, Marguet et $\mathrm{al}^{12}$ and Le Bourgeois et $\mathrm{al}^{13}$ reported no correlation between neutrophil counts and BAL cultures in a similar age group. In the former's study, viral detection was not performed, and not all patients received ICS. In the latter study, viral and bacterial culture studies were not performed on all BAL samples. Le Bourgeois et $\mathrm{al}^{13}$ found no difference between atopic and non-atopic children [?] 36 months (all on ICS). In another study that included an older sample of patients (up to 11.9 years) Najafi et $\mathrm{al}^{14}$ showed neutrophilic inflammation both with and without bacterial infection in the airways of wheezy children, however, a correlation existed. Our study confirms a strong correlation between neutrophilic inflammation and positive bacterial $(\mathrm{p}<0.001)$ and viral cultures $(\mathrm{p}=0.01)$ that is independent of API status. We also report normal BAL cytology for children with non-infected BAL fluid who are unresponsive to asthma therapy regardless of API status. One potential explanation for that could be the observation made by Martinez et $\mathrm{al}^{24}$ that diminished airway function present shortly after birth predicts the recurrent lower respiratory tract infections and recurrent wheezing in the first three years of life. We did not have pulmonary function testing studies for the children in this study and thus cannot evaluate if the non-inflamed, culture negative group represents the transient early wheeze group described in the Tucson Children's Respiratory Study.

We found no increase in eosinophils in the BAL of uncontrolled wheezy preschool children in either API groups. Our definition of high eosinophil percentage was [?]2\%. The role of eosinophilic inflammation in preschool children with asthma and wheezing has not been completely clarified, although it is considered important to guide anti-inflammatory therapy. Elevated BAL eosinophils are a common finding in adults and older children with asthma, which makes this finding in our study somewhat surprising. It is interesting that no difference was found comparing the API groups. We are unaware of any study looking at young preschool children reporting eosinophilic inflammation in their BAL. One study by Thavagnanam et $\mathrm{al}^{25}$ reported increased eosinophils in the BAL of children [?] 36 months who later developed wheezing using a lower cut-off value to define high eosinophils (1.5\%) that we consider normal rather than increased. Marguet et $\mathrm{al}^{12}$ found no eosinophils in the BAL of wheezy infants (regardless of ICS therapy), however, eosinophil percentages were high in the BAL of older wheezy children (median age 7 years). A similar finding was reported by $\mathrm{Najafi}^{14}$ et al for children who were not receiving anti-inflammatory therapy. Ferreira et al ${ }^{26}$ didn't find elevated eosinophils comparing atopic and non-atopic children (mean age 4.7 years), half of them receiving ICS. Looking at children [?] 36 months of age, Le Bourgeois et al ${ }^{13}$ reported no eosinophils in 
BAL of atopic and non-atopic wheezy children unresponsive to ICS. When looking at endobronchial biopsies rather than BAL fluid cytology, Sagalani et $\mathrm{al}^{27}$ reported eosinophilic inflammation in the biopsies from wheezy preschool children (mean age 29 months, $62 \%$ on ICS) compared to their controls. Other studies have documented an increase in eosinophil cationic protein (ECP) in BAL of a younger pediatric population, although this did not correlate with atopy ${ }^{28}$. Whether the lack of eosinophils is due to the confounding effect of inhaled corticosteroid therapy, especially in severe uncontrolled wheezing, or is related to the method of sampling the airways (BAL sampling compared to bronchial biopsies) is unknown. However, it suggests that $\mathrm{PBB}$ rather than uncontrolled eosinophilic inflammation was responsible for continued symptoms in the API+ve group.

The utility of LLM as a marker of aspiration has been controversial since they can be elevated in several inflammatory conditions. However, similar to several studies ${ }^{29}$, we found no correlation between LLM percentages and neutrophils. LLM didn't correlate with other cell types in the BAL of our patients. LLM percentages didn't differ by API status, culture status, or age.

Our study is limited by its small size and retrospective nature. Its small size leaves it underpowered to demonstrate a significant difference in neutrophil counts between the API groups, where interestingly, a trend toward higher counts in the API positive group was seen. The study population included only difficultto-control children on ICS therapy independent of API status and may not reflect findings in steroid naive children. However, for ethical reasons, this will remain a challenge for future investigators and until a well standardized, non-invasive method to study airway inflammation in infants and young children is developed. No control group was evaluated in our study and findings were compared to normal values published in pediatric pulmonary literature ${ }^{10}$. All children were on mild-moderate doses of inhaled steroids, the effect of which cannot be controlled for given the ethical considerations that preclude stopping or delaying treatment in this group especially. Some data suggests no effect of ICS on BAL cytology comparing the treated and untreated children ${ }^{11,30}$. Also, molecular viral detection techniques such as RT-PCR were not used, which are more sensitive than viral cultures.

In conclusion, protracted bacterial bronchitis (PBB) plays an important role in the persistence of respiratory symptoms for children [?]36 months of age unresponsive to ICS therapy regardless of API status. This should be considered prior to increasing anti-inflammatory therapy in this group of children. There was no difference in BAL cell cytology comparing API negative and positive children [?] 36 months old with recurrent respiratory symptoms that are unresponsive to inhaled corticosteroids. Neutrophilic inflammation correlates strongly with BAL viral and bacterial infections and is absent in non-infected lavages. Until a more standardized non-invasive method to investigate airway inflammation in young children is adopted, utilizing BAL fluid cytology will continue to be an important tool in the management of children with chronic recurrent wheeze.

\section{References:}

1. Zahran HS, Bailey CM, Damon SA, Garbe PL, Breysse PN. Vital Signs: Asthma in Children - United States, 2001-2016. MMWR Morb Mortal Wkly Rep. 2018 Feb 9;67(5):149-155.

2. Martinez F, Wright A, Taussig L, Holberg C, Halonen, Morgan W, and the Group Health Medical Associates. Asthma and Wheezing in the First Six Years of Life. N Engl J Med. 1995; 332:133-8.

3. Wright A, Taussig L, Ray C, Harrison H, Holberg C. The Tucson children's Respiratory Study. II. Lower respiratory tract illness in the first year of life. Am J Epidemiol. 1989;129:1232-46.

4. Sherriff A, Peters TJ, Henderson J, Strachan D; ALSPAC Study Team. Avon Longitudinal Study of Parents and Children Risk factor associations with wheezing patterns in children followed longitudinally from birth to 3(1/2) years. Int J Epidemiol. 2001 Dec;30(6):1473-84.

5. Just J, Gouvis-Echraghi R, Couderc R, Guillemot-Lambert N, Saint-Pierre P. Novel severe wheezy young children phenotypes: boys atopic multiple-trigger and girls nonatopic uncontrolled wheeze. J Allergy Clin Immunol. 2012;130(1):103.

6. Casrto-Rodriguez J, C threine J Holberg, Wright A, Martinez F. A Clinical Index to Define Risk of Asthma in Young Children with Recurrent Wheezing. Am J Respir Crit Care Med. 2000;162:1403-6. 
7. Castro-Rodriguez J. The Asthma Predictive Index: early diagnosis of asthma. Curr Opin Allergy Clin Immunol. 2011 Jun;11(3):157-61.

8. Castro-Rodriguez J. The asthma predictive index, a very useful tool for predicting asthma in young children with recurrent wheezing. J Allergy Clin Immunol. 2010 Aug;126(2):212-6.

9. Lee DH, Kwon JW, Kim HY, Seo JH, Kim HB, Lee SY, Jang GC, Song DJ, Kim WK, Jung YH, Hong SJ, Shim JY. Asthma predictive index as a useful diagnostic tool in preschool children: a cross-sectional study in Korea. Clin Exp Pediatr. 2020 Mar;63(3):104-9.

10. Bisgaard H, Hermansen MN, Bønnelykke K, Stokholm J, Baty F, Skytt NL, Aniscenko J, Kebadze T, Johnston SL. Association of bacteria and viruses with wheezy episodes in young children: prospective birth cohort study. BMJ. 2010 Oct 4;341:c4978. doi: 10.1136/bmj.c4978. PMID: 20921080; PMCID: PMC2950260.

11. Krawiec ME, Westcott JY, Chu HW, et al: Persistent wheezing in very young children is associated with lower respiratory inflammation. Am J Respir Crit Care Med. 163:1338-43, 2001.

12. Marguet C, Jouen-Boedes F, Dean TP, Warner JO . Bronchoalveolar cell profiles in children with asthma, infantile wheeze, chronic cough, or cystic fibrosis. Am J Respir Crit Care Med. 1999 May;159(5 Pt 1):1533-40.

13. Le Bourgeois M, Goncalves M, Le Clainche L, et al: Bronchoalveolar cells in children $<3$ years old with severe recurrent wheezing. Chest. 2002;122(3):791-7.

14. Najafi N, Demanet C, Dab I, De Waele M, Malfroot A. Differential cytology of bronchoalveolar lavage fluid in asthmatic children. Pediatr Pulmonol. 2003 Apr;35(4):302-8.

15. National Asthma Education and Prevention Program. Expert Panel Report 3: Guidelines for the Diagnosis and Management of Asthma (EPR-3), 2007.

16. Global initiative for Asthma. Global Strategy for Asthma Management and Prevention, 2020.

17. Bradley E. Chipps. Long-Term Inhaled Corticosteroids in Preschool Children at High Risk for Asthma. Pediatr 2007;120;S140.

18. Chang AB, Glomb WB. Guidelines for evaluating chronic cough in pediatrics: ACCP evidence-based clinical practice guidelines. Chest. 2006 Jan;129(1 Suppl):260S-283S. doi: 10.1378/chest.129.1_suppl.260S. PMID: 16428719.

19. De Schutter I, Dreesman A, Soetens O, De Waele M, Crokaert F, Verhaegen J, Piérard D, Malfroot A. In young children, persistent wheezing is associated with bronchial bacterial infection: a retrospective analysis. BMC Pediatr. 2012 Jun 22;12:83.

20. Schwerk N, Brinkmann F, Soudah B, Kabesch M, Hansen G. Wheeze in Preschool Age Is Associated with Pulmonary Bacterial Infection and Resolves after Antibiotic Therapy. PLoS One. 2011;6(11):e27913.

21. Kantar A, Chang AB, Shields MD, Marchant JM, Grimwood K, Grigg J, Priftis KN, Cutrera R, Midulla F, Brand PLP, Everard ML. ERS statement on protracted bacterial bronchitis in children. Eur Respir J. 2017 Aug 24;50(2):1602139. doi: 10.1183/13993003.02139-2016. PMID: 28838975.

22. De Blic J, Midulla F, Barbato A, Clement A, Dab I, Eber E, Green C, Grigg J, Kotecha S, Kurland G, Pohunek P, Ratjen F, Rossi G. Bronchoalveolar lavage in children. ERS Task Force on bronchoalveolar lavage in children. European Respiratory Society. Eur Respir J. 2000 Jan;15(1):217-31.

23. Bisgaard H, Hermansen MN, Buchvald F, Loland L, Halkjaer LB, Bønnelykke K, Brasholt M, Heltberg A, Vissing NH, Thorsen SV, Stage M, Pipper CB. Childhood Asthma after Bacterial Colonization of the Airway in Neonates. N Engl J Med. 2007;357:1487-95.

24. Martinez F. what we have learned from Tucson children's respiratory study. Paediatr Respir Rev. 2002 Sep;3(3):193-7.

25. Thavagnanam S, Williamson G, Ennis M, Heaney LG, Shields MD.Does airway allergic inflammation pre-exist before late onset wheeze in children? Pediatr Allergy Immunol. 2010: 21: 1002-7.

26. Ferreira Fde A, Filho LV, Rodrigues JC, Bush A, Haslam PL. Comparison of Atopic and Nonatopic Children With Chronic Cough: Bronchoalveolar Lavage Cell Profile. Pediatr Pulmonol. 2007 Oct; 42(10):857-63.

27. Saglani S, Payne DN, Zhu J, Wang Z, Nicholson AG, Bush A, Jeffery PK.Early Detection of Airway 
Wall Remodeling and Eosinophilic Inflammation in Preschool Wheezers. Am J Respir Crit Care Med . Am J Respir Crit Care Med. 2007 Nov 1;176(9):858-64.

28. Azevedo I, de Blic J, Vargaftig BB, Bachelet M, Scheinmann P. Increased eosinophil cationic protein levels in bronchoalveolar lavage from wheezy infants. Pediatr Allergy Immunol. 2001 Apr;12(2):65-72.

29. Reilly BK, Katz ES, Misono AS, Khatwa U, Didas A, Huang L, Haver K, Rahbar R. Utilization of Lipid-Laden Macrophage Index in Evaluation of Aerodigestive Disorders. Laryngoscope. 2011 May;121(5):1055-9.

30. De Baets F, De Schutter I, Aarts C, Haerynck F, Van Daele S, De Wachter E, Malfroot A, Schelstraete P. Malacia, Inflammation and BAL culture in children with persistent respirator symptoms. Eur Respir J. 2012 Feb; 39(2):392-5.

\section{Hosted file}

Mansucript table-1.pdf available at https://authorea.com/users/408251/articles/518331bronchoalveolar-lavage-profiles-in-uncontrolled-wheezy-children-compared-by-asthmapredictive-index

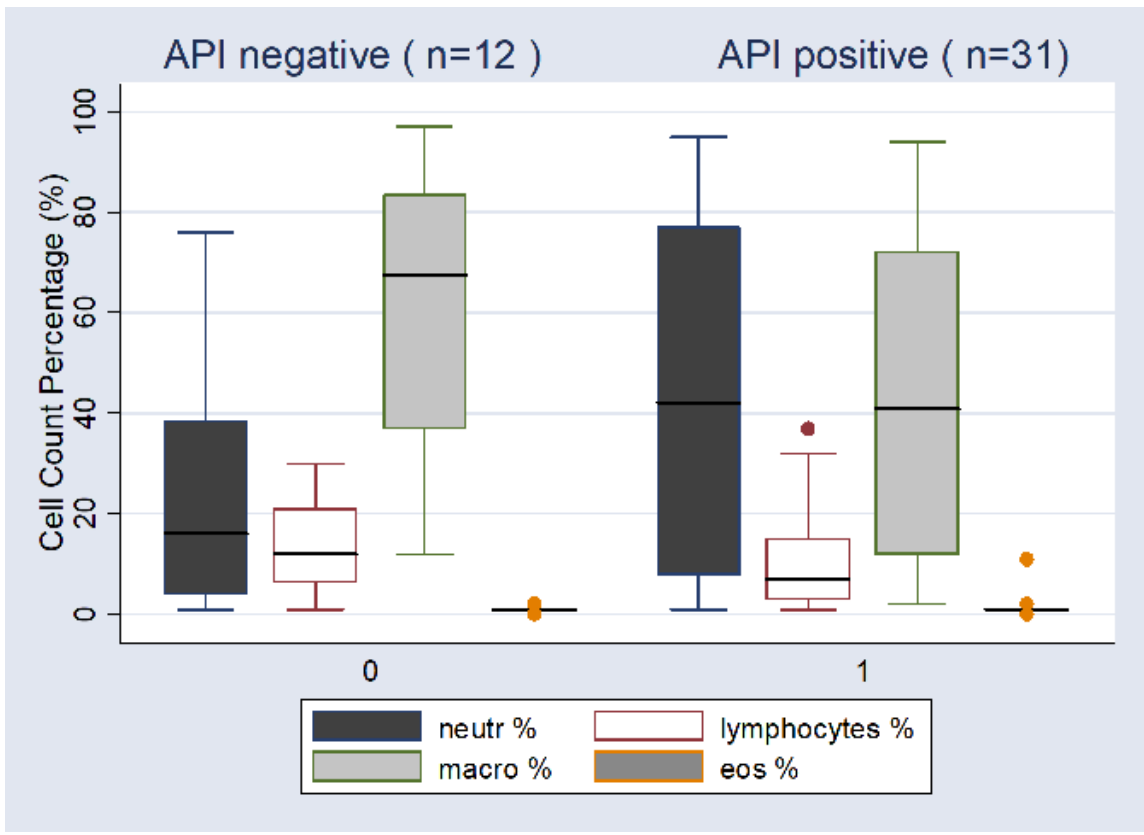




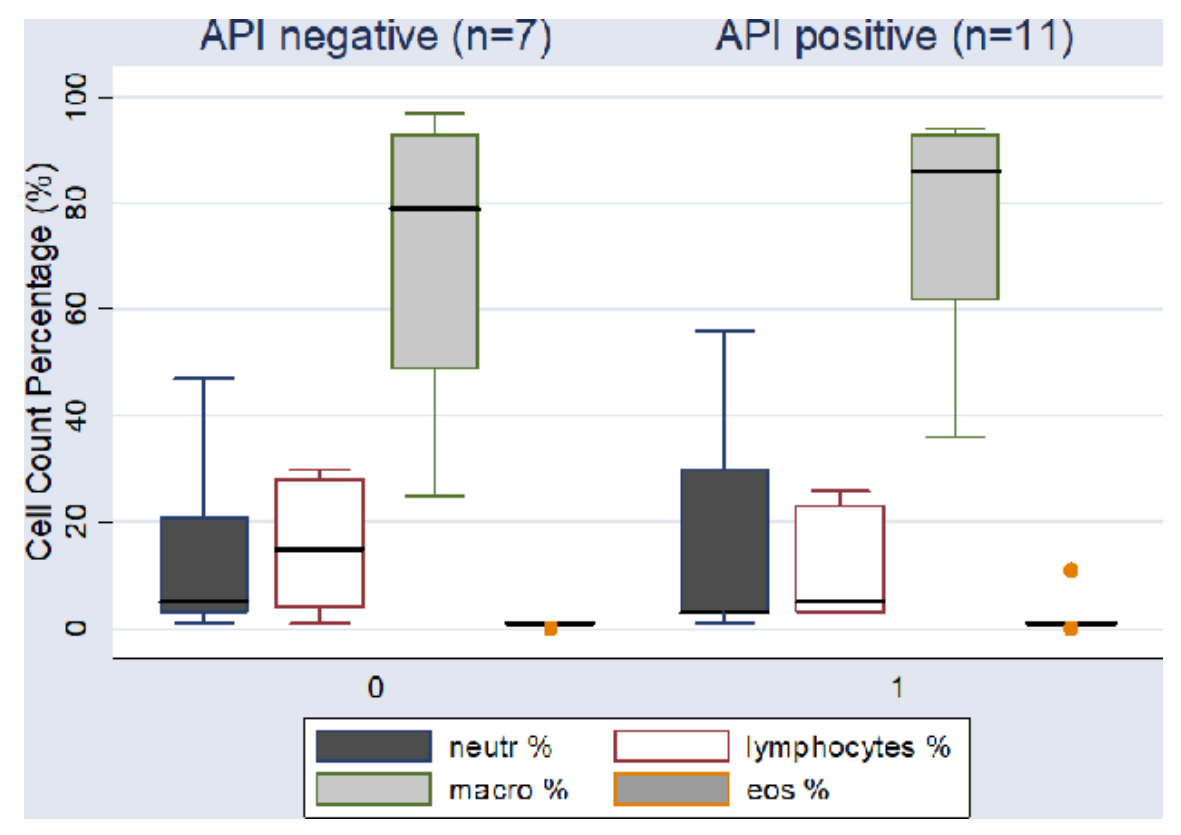

\section{Hosted file}

Manuscript table-2.pdf available at https://authorea.com/users/408251/articles/518331bronchoalveolar-lavage-profiles-in-uncontrolled-wheezy-children-compared-by-asthmapredictive-index

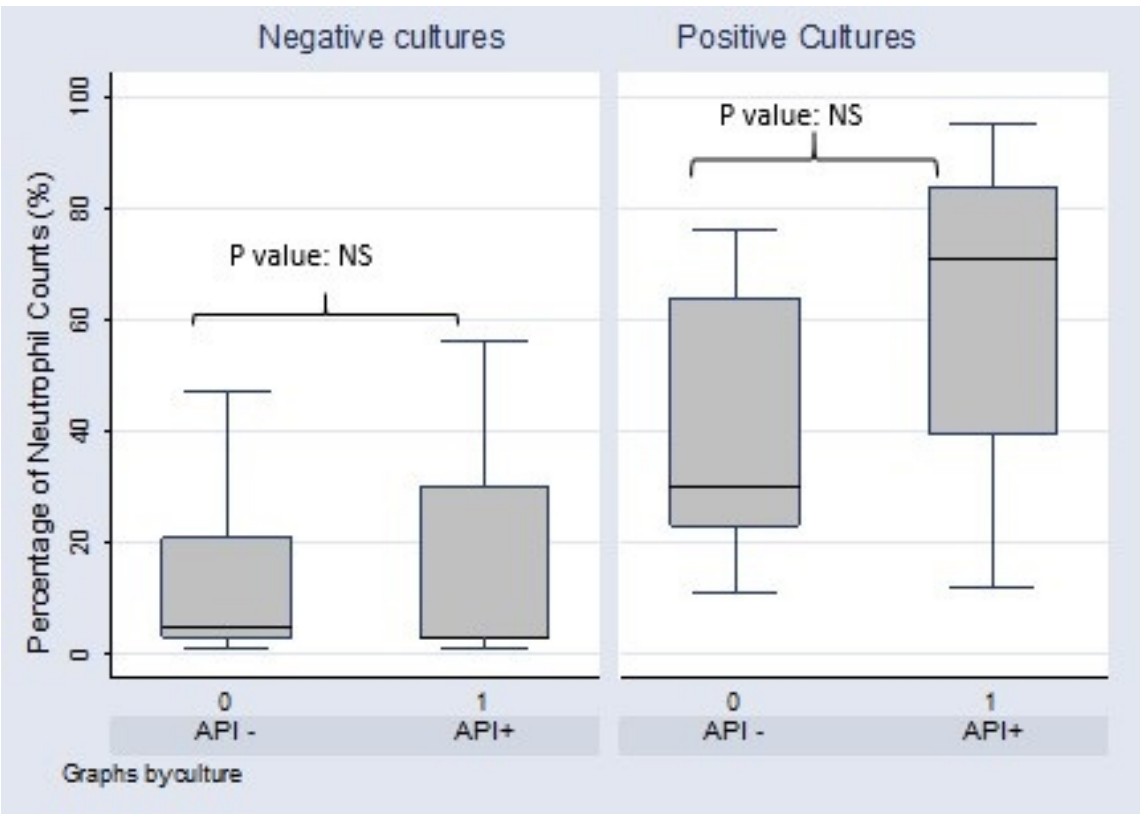

